\title{
LA IMAGEN DEL ARZOBISPO Y CARDENAL FRANCISCO ANTONIO DE LORENZANA
}

\author{
POR \\ CÁNDIDO DE LA CRUZ AlCAÑIZ \\ Escuela española de Historia y Arqueología en Roma - CSIC
}

Francisco Antonio de Lorenzana y Buitrón (1722-1804) como personaje histórico genera una proyección advertida en una imagen continuada. Damos a conocer y analizamos los retratos de su etapa como arzobispo de México (1766-1772) y como arzobispo de Toledo (1772-1800), testimonios de su actividad social.

Palabras clave: Francisco Antonio de Lorenzana; Imagen; Retrato; Representación cultural.

Francisco Antonio de Lorenzana y Buitrón (1722-1804) as an historic personage generates a projection in a continuous image. The author presents and analyses the portraits from his period as Archbishop of Mexico (1766-1772) and those from his period as Archbishop of Toledo (1772-1800), all testimonies of his social activities.

Key words: Francisco Antonio de Lorenzana; Image; Portrait; Cultural Representation.

El retrato supera al hombre en cuanto le permite subsistir sin su presencia y finalmente sobrevivir en la memoria tras la muerte. Cumple su función de representación social al conllevar unas connotaciones atributivas fácilmente perceptibles por los contemporáneos constituyéndose de esta manera un lenguaje formal donde el retratado es reconocido.

Para el prelado leonés Francisco Antonio de Lorenzana (1722-1804) existen dos etapas claramente diferenciadas que permiten por sí solas apreciar la imagen proyectada: 1766 como arzobispo de México y 1772 como arzobispo de Toledo.

\section{El retrato de Francisco Antonio de Lorenzana en México}

La persistencia del modelo retratístico de la monarquía de la Casa de Austria en el siglo XVIII se evidencia en la figura de cuerpo entero sobre fondo recortado por una cortina, junto con mesas 
de trabajo en las que se indica la actividad intelectual por la que el personaje obtendría la autoridad suficiente como para merecer ser retratado ${ }^{1}$.

El retrato novohispano no constituye un género como tal, sino que se erige como testimonio histórico del retratado más que como la individualización del mismo ${ }^{2}$. Es la presencia lo que importa. Están caracterizados por la rigidez y la repetición de las composiciones, por grandes y lujosos ropajes que ocultan el cuerpo situado en el eje central sobre un fondo en el que cuelga una cortina roja y el escudo heráldico. Al lado, una mesa sobre la cual se disponen los objetos que son propios de la función del retratado. Son cuatro los elementos que se repiten constantemente: cortinaje, mesita con accesorios, el escudo nobiliario y una inscripción con sus datos personales. Así como el bastón indica la calidad de virrey y la mitra o báculo su condición de prelado, los tinteros con plumas nos advierten de la condición de funcionario o su función destacada como escritor, los libros su afición a las letras, y un birrete doctoral nos informa de su grado académico sabiendo incluso si era doctor en teología, cánones, filosofía, medicina o jurisprudencia de acuerdo al color de las borlas ${ }^{3}$.

El 13 de febrero de 1766 se produciría el nombramiento de Francisco Antonio de Lorenzana como arzobispo de México. Tomando como origen el Cabildo de la catedral de Toledo, surge en Nueva España en la segunda mitad del siglo XVIII un movimiento intelectual basado en el regalismo e impregnado por las ideas democráticas y nacionalistas conciliares hundiendo sus esquemas en la historia de la Iglesia española. Este grupo estuvo formado por el propio Lorenzana, Francisco Fabián y Fuero y Alonso Núñez de Haro 4 .

En el Banco Nacional de México se encuentra un retrato realizado por Miguel Cabrera (fig. 1). Éste será el retrato de Francisco Antonio de Lorenzana que más difusión alcanzaría en América constituyéndose como modelo. Tal y como expone Beatriz Mackenzie, el cuadro contiene la fecha de 1765 , lo que supone haberse realizado un año antes de la llegada del arzobispo mexicano ${ }^{5}$.

Miguel Cabrera fue el pintor de cámara del arzobispo Rubio y Salinas durante su arzobispado (1749-1765) y así se refleja en la portada de Maravilla americana y conjunto de raras maravillas publicada en $1756^{6}$. Esta publicación tiene su génesis en el encargo que el abad de la Colegiata de Guadalupe hizo a los pintores más famosos de México a fin de que inspeccionasen la imagen de la Virgen, sin el cristal que lo protegía, el 30 de abril de $1751^{7}$. Otro acontecimiento en el que participó Cabrera fue la fundación de una Academia de Bellas Artes en 1753 en la que sería nombrado presidente perpetuo ${ }^{8}$. Ésta sería la antecedente de la fundada en 1778 bajo el nombre

\footnotetext{
${ }^{1}$ RodríGUez Moya, Inmaculada, La mirada del virrey. Iconografía del poder en la Nueva España, Universidad Jaime I, Castellón de la Plana, 2004, p. 37.

2 Vargaslugo, Elisa, "Comentarios sobre la colección de retratos", en AA.VV., Pintura Novohispana. Museo Nacional del Virreinato, III vol., Amigos del Museo Nacional del Virreinato, México, 1996, p. 21.

3 Ruiz Gomar, Rogelio, "La pintura de retrato en la Nueva España", en Mackenzie, Beatriz (coord.), El retrato novohispano en el siglo XVIII, Museo poblano de arte virreinal, México, 2000, pp. 9-10.

4 Jover Zamora, José María (dir.), Historia de España de Menéndez Pidal. La época de la Ilustración, t. 31, vol. II, Espasa Calpe, Madrid, 1988, p. 336.

${ }_{5}^{5}$ MaCkenZIE, Beatriz (coord.), El retrato novohispano en el siglo XVIII, Museo poblano de arte virreinal, México, 2000, cat. 32, p. 119. Se encuentra firmado Michael Cabrera pinxit anno Domini 1765.

${ }^{6}$ Biblioteca Nacional de Madrid (B.N.M.), 2/2347, Maravilla americana y conjunto de raras maravillas, observadas con la direccion de las reglas del arte de la pintura en la prodigiosa imagen de Nra. Señora de Guadalupe de Mexico por D. Miguel Cabrera, Pintor del ilustrisimo señor D. D. Manuel Josef Rubio y Salinas, dignisimo Arzobispo de Mexico, y del Consejo de su Majestad a quien se la consagra 1756, en Colección de obras y opúsculos pertenecientes a la aparición de nuestra señora de Guadalupe de México, Madrid, 1785, pp. 612-644.

7 Toussaint, Manuel, Pintura colonial en México, U. Nacional Autónoma de México, México, 1990, p. 161.

8 Idem.
} 


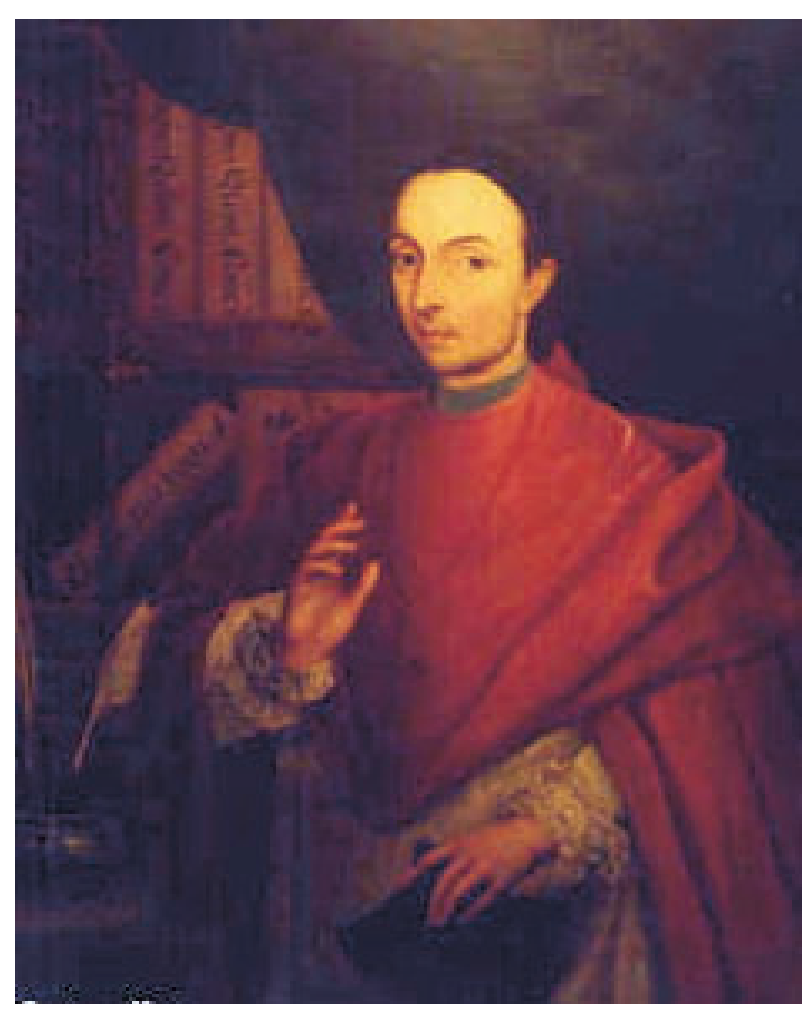

Fig. 1. Miguel Cabrera, Francisco Antonio de Lorenzana, México, Banco Nacional.

de San Carlos. Moriría el 16 de mayo de 1768 en México siendo enterrado -bajo licencia de Lorenzana- en la iglesia de Santa Inés ${ }^{9}$. Los modos empleados por Cabrera en los retratos de José Antonio Flores y Rivera ${ }^{10}$, obispo de Nicaragua, realizado en 1757 y del arzobispo Rubio y Salinas ${ }^{11}$ constituyen los tipos comunes del retrato mexicano de la época.

Otro retrato de Lorenzana, también efectuado por Miguel Cabrera, es el del Museo Nacional del Virreinato de México ${ }^{12}$ (fig. 2) y que reproduce fielmente al anterior. Se superpone sobre un fondo de cortinaje verde, con capa roja y cruz pectoral. En el fondo se aprecia la mitra y el crucifijo $^{13}$. Está firmado en el ángulo inferior derecho "Michel Cabrera Pinxt. Anno Domini 1766" y en la leyenda se puede leer "Illmo. Sor. Dn. Francisco Antonio de Lorenzana Buitrón, Collegial mayor de San Salbador del Obispado de Oviedo de la Ciudad de Salamanca, Canonigo Doctoral de la Sta. Iglesia Catedral de Sigüenza; Canonigo, y Vicario general de la Sta. Iglesia Primada

9 Carrillo y Cariel, Abelardo, El pintor Miguel Cabrera, Instituto de Antropología e Historia, México, 1966, p. 9, y Toussaint, Manuel, op. cit., p. 162.

10 Toussaint, Manuel, op. cit., fig. 313.

11 CARrillo y CARIEL, Abelardo, op. cit., fig. 13, p. 61.

12 Ibid., p. 9 y AA.VV., Pintura Novohispana. Museo Nacional del Virreinato, op. cit., III vol., p. 199.

13 Carrillo y Cariel, Abelardo, op. cit., fig. 20, p. 68, Romero Flores, Jesús, Iconografía colonial, Museo Nacional, México, 1940, p. 127, Bonet Correa, Antonio, "El cardenal Lorenzana y el arte mexicano", en Actas del V Simposio Hispano-Portugués de Historia del Arte. Relaciones artísticas entre la Península Ibérica y América, Valladolid, 1990, p. 44. Coincide con el analizado por Toussaint perteneciente a la Colección de Manuel Romero de Terreros. 


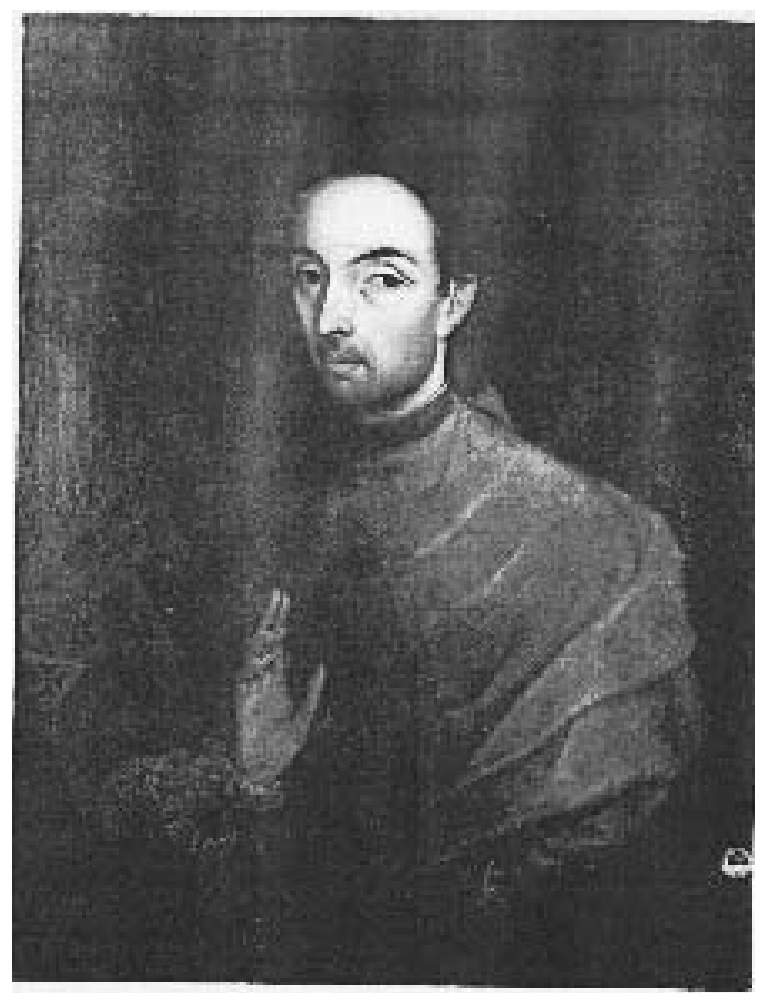

Fig. 2. Miguel Cabrera, Francisco Antonio de Lorenzana, Tepotzotlán (México), Museo Nacional del Virreinato.

de Toledo, Abád de Sn. Vizente, Dignidad de dicha Sta. Primada Iglesia del Consejo de S.M. Obispo de Plasencia y actualmente Arzobispo de Mexico". La cartela constituye el elemento más importante de los retratos novohispanos que al ser tan sumamente tipificados la necesitan para reconocer la figura, siendo también importante su función rememorativa al presentarse en forma de hoja curricular.

Manuel Toussaint afirma la mala calidad generalizada de la obra del pintor oaxaqueño aduciendo motivos de gusto estético basados en pinturas suaves y sin vigor excesivo ${ }^{14}$, pero esta afirmación la extiende al último cuarto del siglo XVII alargándola a todo el siglo XVIII. El siglo XVII mexicano es considerado como la etapa de esplendor pictórica afirmando que en el siguiente siglo la pintura se torna ordinaria ${ }^{15}$. Sin embargo, Miguel Cabrera dominaría el panorama pictórico mexicano en la segunda mitad del XVIII resultando evidente su huella en los pintores que le sucedieron.

En el Ateneo Español de México se encuentra un retrato de Lorenzana que sigue muy de cerca el modelo impuesto por Miguel Cabrera ${ }^{16}$ (fig. 3). Sin llegar a alcanzar la complejidad

14 Toussaint, Manuel, op. cit., p. 167.

15 Ibid., p. 136.

${ }^{16}$ Llamazares Rodríguez, Fernando, "Imagen e imágenes de los arzobispos de Toledo", en Llamazares, Fernando y Vizuete Mendoza, Juan Carlos (coords.), Arzobispos de Toledo, Mecenas Universitarios, Universidad de Castilla-La Mancha, Cuenca, 2004, pp. 166-167. 
facial del rostro que el retrato de Lorenzana alcanzará en España, la pintura novohispana transmite la personalidad del retratado a través de símbolos. En este caso, y siempre en repetición, la mitra episcopal de Plasencia que Lorenzana había ostentado entre 1765 y 1766, la mitra arzobispal de México con el palio atestiguando su posesión, el tintero que acentúa su faceta de escritor y el birrete y la borla azul como doctor en cánones. El escudo no presenta ningún bordón que haga alusión a su cargo como arzobispo. La representación cultural de la figura actúa como testimonio de su presencia. A través de la cartela constatamos que esta pintura anónima se ideó para la conmemoración de la posesión del arzobispado de México: "EL ILLMO SR DR/ D Francisco Antonio/ de Lorenzana y Buitrón/ Collegial que fue en el mayor de/ San Salvador de Oviedo de la Ciu/ dad de Salamanca, Canónigo Doctoral/ de la Santa Iglesia Catedral de Sigu/ enza, Canónigo y Vicario General/ de la de Toledo Primada de las/ Españas: Abad de San Vicente/ dignidad de dicha Canta Iglesia Pri/ mada del Consejo de su Majestad/ Obispo de Plazencia y actual/ Dignísimo Arzobispo de esta/ Santa Metropolitana Iglesia de/ México. Tomo posesión de/ el arzobispado en 22 de/ Agosto de mil setecientos/ y 66 y recibió el Santo Palio/ en 8 de setiembre. Natural de la Ciu/ dad de León”.

Tras la marcha de Lorenzana a Toledo en 1772 aparecerán dos cuadros que sirven de homenaje a su memoria. El primero de ellos (fig. 4) muestra tres mitras episcopales, dos de ellas con palio como referencia a los arzobispados de México y Toledo, la Orden de Carlos III otorgada en 1772 y el birrete haciendo alusión a su nombramiento como cardenal en 1789. Este último hecho es resaltado en la leyenda dejando claro el alto orden jerárquico que el antiguo arzobispo mexicano ostentaba en el momento del retrato: “(...) CARDENAL PRESBITERO/ de la Sta. Romana Iglesia en el/ Consistorio tenido en el Va/ ticano en 30 de Marzo/ de 1789". La influencia del retrato de Cabrera es tal que los posteriores artistas se limitan a imitar su figura y rostro completando solamente los datos y símbolos que se añaden en su carrera. De esta manera y siendo una excepción en el retrato mexicano (otro ejemplo lo podemos observar en el retrato de Palafox ${ }^{17}$ ) la figura quedará fijada y representada con sus rasgos faciales a modo de arquetipo.

De similares características es el retrato que sirvió para honrar su memoria en el Real Pontificio Seminario al que Lorenzana había dejado su biblioteca personal: “(...) Haviendo dexa/ do á este Real Pontifico Seminario, su Se/ lecta copiosa Biblioteca, que le tenia dona/ da antes de su Eleccion, para prueba de su sin/gular amor, y atención con que miro siempre/ al Colegio, y a todos su Alumnos" (fig. 5). Salvo algunos elementos accesorios el presente lienzo es una reutilización del anterior. Cabe la hipótesis de que el autor sea el mismo atendiendo a la disposición del suelo y a la forma de la orla que cierra la cartela. Se observa de forma más clara la composición de la biblioteca del arzobispo, en el que destacan los volúmenes del Concilio provincial mexicano y de la Summa Theologiae de Santo Tomás de Aquino. La formación tomista recibida se inicia en la carrera del prelado leonés en el priorato benedictino de San Andrés en Espinareda y continuaría en el Colegio de San Vicente en Salamanca ${ }^{18}$. Durante el siglo XVIII la utilización de la teología tomista será un recurso considerado como infalible ${ }^{19}$.

\footnotetext{
17 Véase FernÁNDEZ Gracia, Ricardo, Iconografia de Don Juan de Palafox. Imágenes para un hombre de Estado $y$ de Iglesia, Gobierno de Navarra, 2002.

18 Sierra Nava-Lasa, Luis, El Cardenal Lorenzana y la Ilustración, Fundación Universitaria Española, Madrid, 1975 , pp. 35-37 y 64.

19 "Aristóteles, Escoto y Santo Tomás son para ellos oráculos tan infalibles, que si alguno pensara en no seguir ciegamente a uno de los tres, nunca podría aspirar a ser tenido por buen Filósofo", en Vayrac, Etat present de l'Espagne, 1716, citado en MARÍAS, Julián, La España posible en tiempo de Carlos III (1963), Planeta, Barcelona, 1988, p. 76.
} 


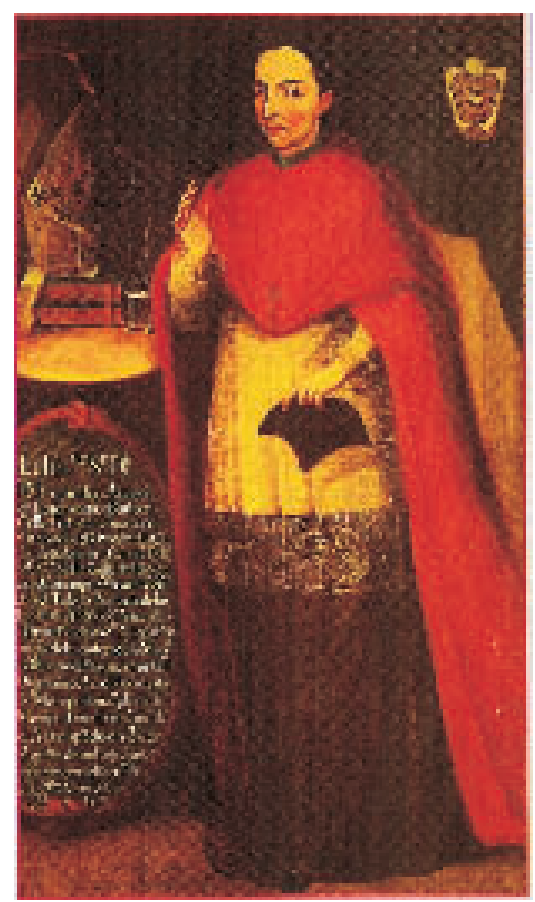

Fig. 3. Anónimo, Francisco Antonio de Lorenzana, México, Ateneo español.

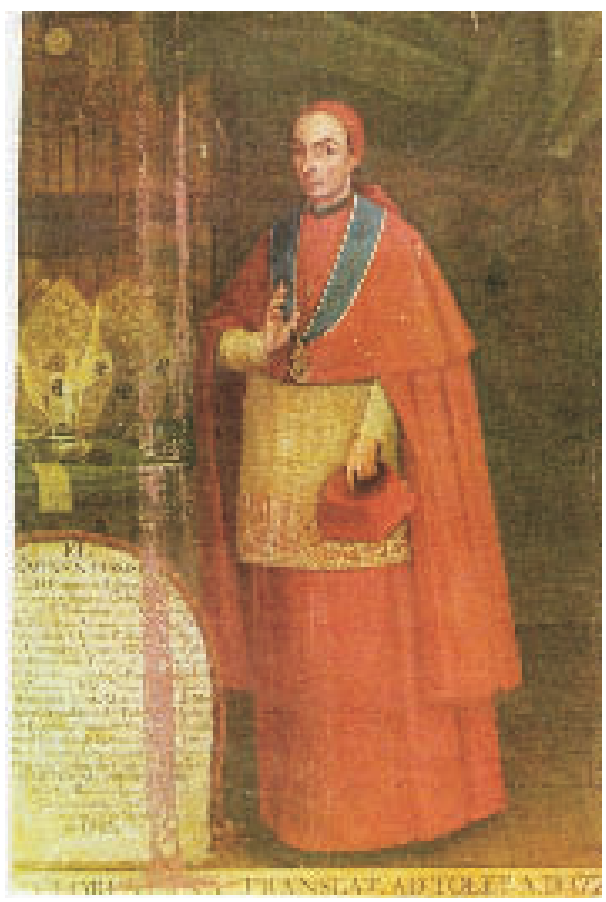

Fig. 4. Anónimo, Francisco Antonio de Lorenzana, Paradero desconocido.

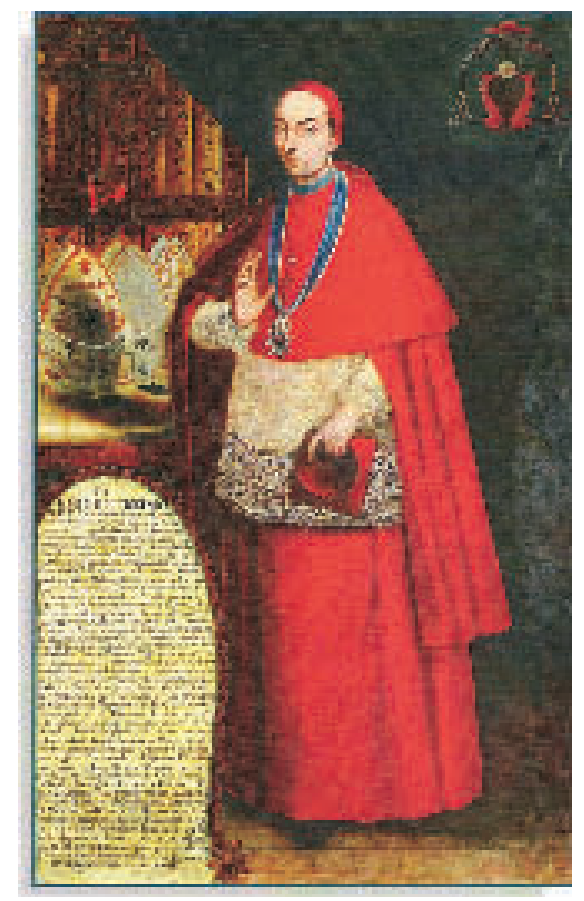

Fig. 5. Anónimo, Francisco Antonio de Lorenzana, México, catedral. 
Dentro de la imagen extrínseca, nos ha llegado una acuarela (fig. 6) del manuscrito del IV Concilio Provincial mexicano en la que se representa una de las sesiones con Lorenzana en el centro de la mesa de la derecha, el virrey bajo dosel, los obispos, secretarios, padres conciliares, consultores, asistentes, clérigos y seglares ${ }^{20}$. El IV Concilio Provincial Mexicano junto con su índice de celebración -Tomo Regio- fue un instrumento de Carlos III para probar la amplitud de las tesis reformadoras en un territorio donde se tenía una increíble maniobrabilidad a raíz del Concordato de 1753. Así, Carlos III se autoproclamaría en 1765 vicario y delegado de la Silla Apostólica aduciendo que "compete a mi real potestad intervenir en todo lo concerniente al gobierno espiritual de las Indias, con tanta amplitud, que no sólo me está concedida por la Santa Sede sus veces en lo económico de las dependencias y cosas eclesiásticas, sino también en los jurisdiccional y contencioso (...)"21. La noticia de la celebración del IV Concilio llegaría a México el 13 de enero de 1770 por mano del virrey, el marqués de Croix, fijando su apertura para el mismo día en $1771^{22}$. El IV Concilio Provincial estuvo formado por los obispos de Puebla, Yucatán, Oaxaca y Durango, el canónigo doctoral Vicente Antonio de los Ríos en sustitución del obispo de Michoacán, Pedro Anselmo Sánchez de Tagle, y el representante del obispado de Guadalajara. Además asistieron diversos capitulares de las iglesias catedrales y colegiatas, seis consultores teólogos, juristas, los provinciales de las órdenes religiosas (dominicos, franciscanos, dieguinos, agustinos, carmelitas, mercedarios, camilos, betlehemitas y juaninos), Antonio Joaquín de Rivadeneira como comisionado real y el fiscal Areche en nombre de la Audiencia ${ }^{23}$. Son éstos los personajes que se dejan intuir en la acuarela.

Lorenzana conseguiría publicar los Concilios I, II (este se encontraba inédito) en cuyo final inserta la Serie de Ilmos. Señores Arzobispos de México terminando con él mismo ${ }^{24}$, símbolo de su autorreconocimiento. La reimpresión del III Concilio actuaba como antesala a la esperada edición del IV que no llegaría a publicarse debido al amplio regalismo observado en sus conclusiones. Este pensamiento advertido durante su arzobispado en México es lo que provocaría que la Curia romana no aprobase las actas del IV Concilio Provincial en las que claramente se manifestaba la superioridad de la imagen regia sobre cualquier manifestación pontificia. Sin embargo, en el pensamiento de Lorenzana se propone la armonía de relaciones de ambas esferas de poder, y aunque las dos provengan de Dios afirma sus distintas finalidades ${ }^{25}$.

Otro lienzo donde se representa a Lorenzana es el que realizara Francisco Antonio Vallejo con motivo de la aprobada letanía Mater Immaculata en 1774 (fig. 7). Organizado en dos planos, en el superior aparece la Virgen con San Pablo y Santa Catalina (patronos de la Real Universidad), Santo Tomás, San Juan Nepomuceno y San Luis Gonzaga. A la derecha de la Virgen se

20 Vizuete Mendoza, Juan Carlos, Llamazares, Fernando y Martín Sánchez, Julio (coords.), Exposición Los arzobispos de Toledo y la Universidad Española, Universidad de Castilla-La Mancha, Cuenca, 2002, fig. 28, pp. 150151.

${ }^{21}$ De La Hera, Alberto, Iglesia y Corona en la América española, Colecciones Mapfre, Madrid, 1992, p. 500.

22 Ibid., p. 275.

${ }^{23}$ Zahino Peñafort, Luisa, El Cardenal Lorenzana y el IV Concilio Provincial Mexicano, Universidad Nacional Autónoma de México, México, 1999, pp. 37-38.

${ }^{24}$ Malagón-Barcelo, Javier, "La obra escrita de Lorenzana como arzobispo de México (1766-1772)”, en RidrueJo, Pedro (coord.), Simposio “Toledo ilustrado”, II vols., Colección “Toledo Universitario", Toledo, 1975, p. 37.

25 "Para firme y buen gobierno instituyó Dios dos grandes dignidades: esto es, la autoridad sacerdotal y pontificia y la potestad real, [...]. La primera tiene por fin la salvación de las almas, y la segunda la paz y quietud, vida civil y temporal de los súbditos. Una y otra traen un mismo origen porque ambas dimanan de Dios y una y otra tienen sus límites que no pasan ni pueden pasar. Y una y a otra, para no resistir a la ordenación y disposición de Dios, se debe obedecer". Citado en MARTínez Albesa, Emilio, "Fundamentos del regalismo en el magisterio episcopal de Francisco Antonio Lorenzana, arzobispo de México (1766-1772)", en Mar Oceana: Revista del humanismo español e iberoamericano, n. $^{\circ} 6,2000$, p. 55 . 


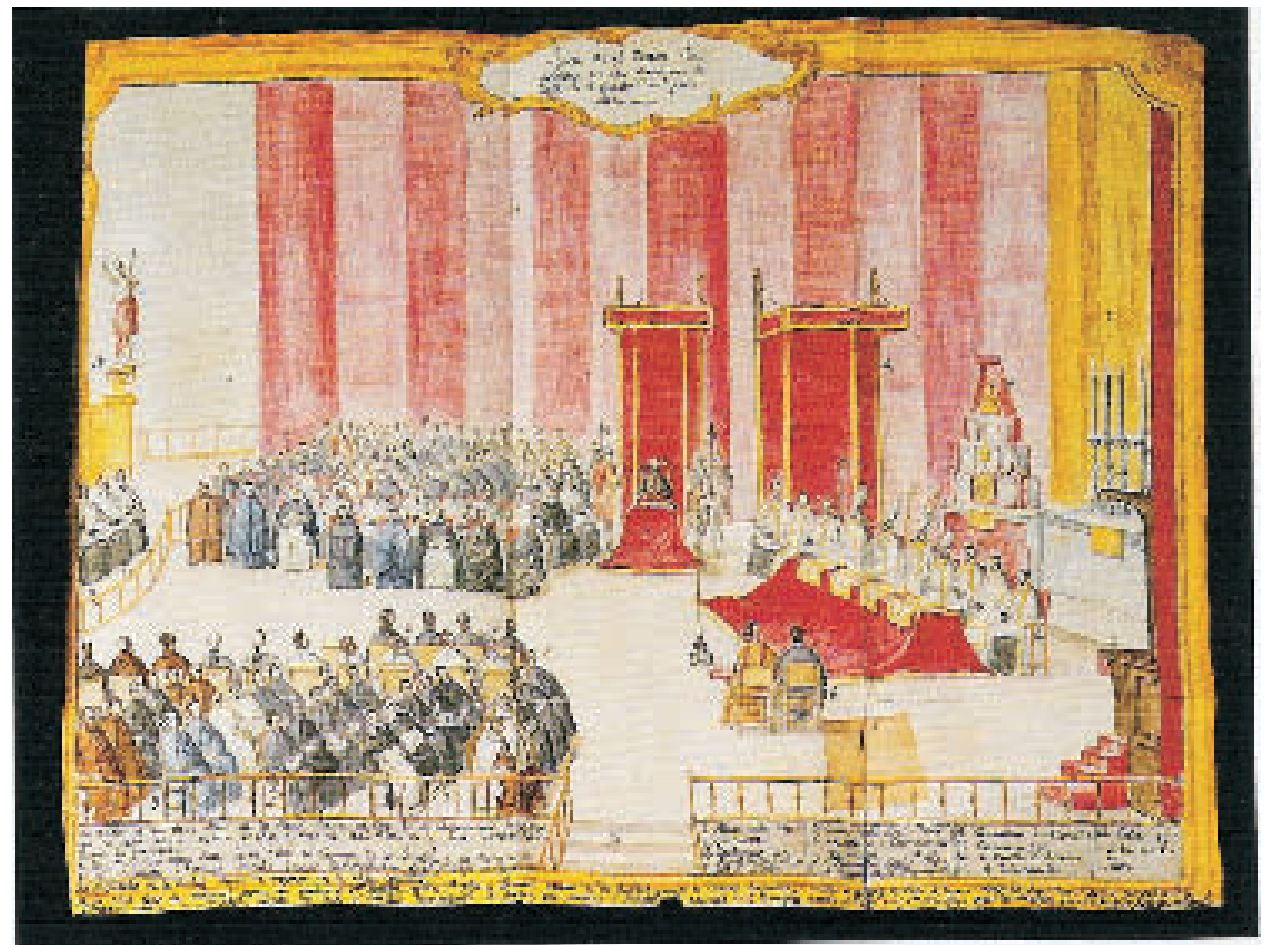

Fig. 6. Anónimo, Sesión del IV Concilio Provincial mexicano, Toledo, Biblioteca Pública.

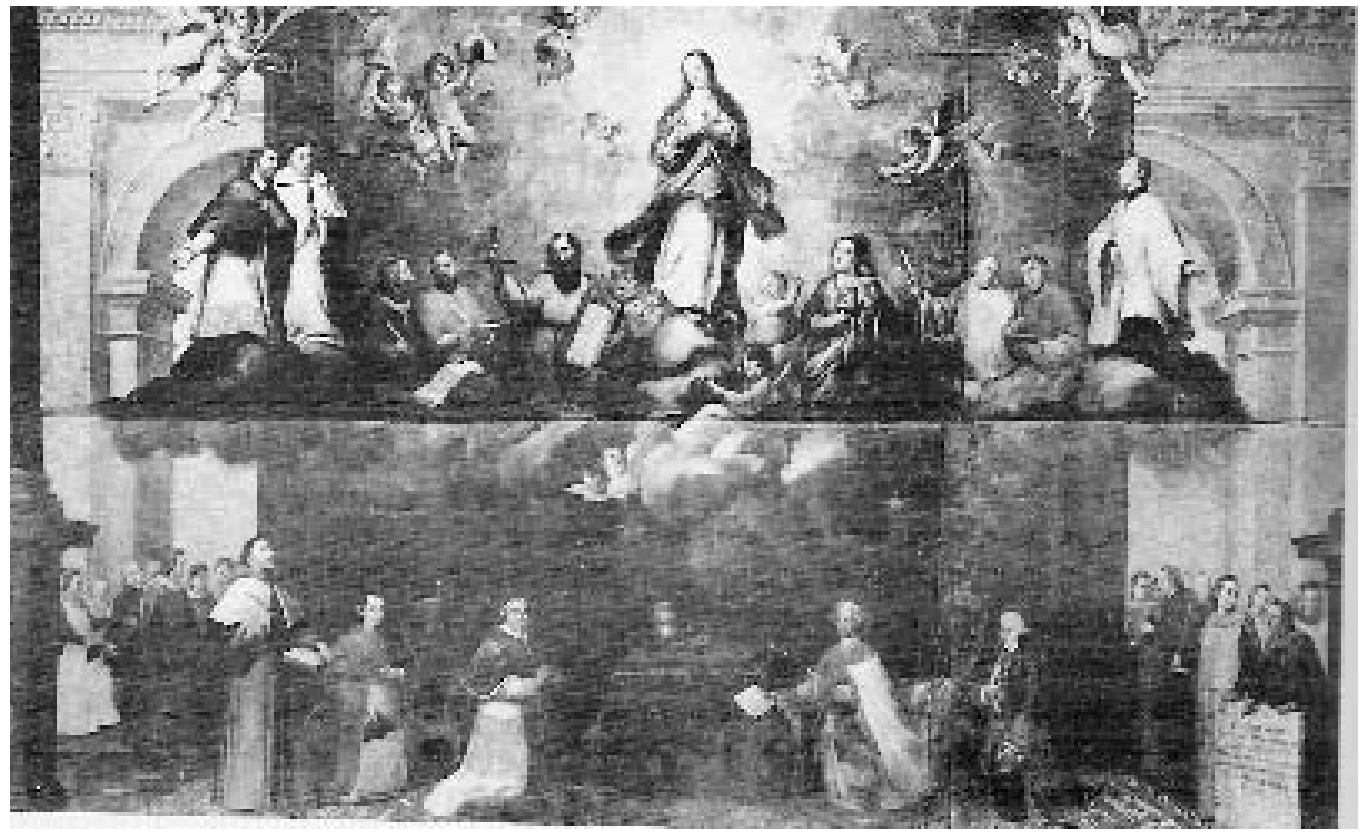

Fig. 7. Francisco Antonio Vallejo, Mater Immaculata, México, Pinacoteca Virreinal. 
disponen los cuatro doctores marianos. En el plano inferior Carlos III, el virrey Bucarelli, el Papa y Lorenzana. A ambos lados se disponen grupos de estudiantes bajo una arquitectura clasicista ${ }^{26}$. La obtención de la precación Mater Immaculata se produjo por un edicto de Clemente XIII en el que se podía rezar y contemplar misa de la Purísima Concepción algunos días al año, además de añadir la mencionada letanía ${ }^{27}$.

Se conservan otros lienzos que se encuentran dentro de la representación circunstancial o extrínseca de Lorenzana a los que no hemos podido acceder. Uno es el Patrocinio de San José de Ventura José Guiol. Según la descripción de Toussaint, bajo la túnica del santo aparecen Carlos III y tres damas y en su lado opuesto Lorenzana y tres sacerdotes. Se conserva en el Museo Michoacano ${ }^{28}$. José María de Alcíbar pintaría en 1774 a todos los miembros del Oratorio de San Felipe Neri, encabezados por el virrey y por Lorenzana, lienzo que se conserva en la Pinacoteca de La Profesa ${ }^{29}$.

Lo que queda reflejado en las representaciones de Lorenzana es el enorme contacto que mantuvo con la sociedad mexicana, cuya memoria perdurará en la realización de retratos tras haber abandonado el arzobispado. Incluso los restos del cardenal serían trasladados por el cabildo mexicano a su catedral en 1956 desde la iglesia romana de Santa Cruz de Jerusalén donde estaba enterrado ${ }^{30}$.

El nombramiento como arzobispo de Toledo lo conocieron los asistentes del IV Concilio el 2 de agosto atribuyendo el mismo Lorenzana su ascenso al mérito y esfuerzo del Concilio y como éste era observado por el Rey ${ }^{31}$. En agosto de 1772 llegaría a México el nuevo arzobispo Alonso Núñez de Haro. El arzobispado toledano de Francisco Antonio de Lorenzana no puede considerarse un simple premio, sino el hallazgo de un personaje con amplia capacidad reformadora y de cuyas adhesiones regalistas no había dudas ${ }^{32}$. La motivación de los ascensos (el arzobispo angelopolitano Fabián y Fuero sería nombrado arzobispo de Valencia) radica en que Carlos III consideraba Nueva España como el instrumento para reconstruir España y renovar su posición mundial, constituyendo la entrada de ingresos, poder y prestigio ${ }^{33}$.

\section{El retrato de Lorenzana en España}

Los retratos de Lorenzana realizados en España cambian con respecto a los efectuados en México. Ahora el centro es el hombre adentrándose en su conocimiento. Gracias a la individualización del rostro se produce la comunicación con el espectador permitiéndonos conocer su función, su carácter y su posición. Evitando todos los atributos que no sean imprescindibles, el lienzo no necesita de la cartela explicativa para reconocer al personaje. El retrato, bajo un naciente neoclasicismo, aspira a la representación cultural del ser a través de una comunicación directa, sin interferencias, plenamente sencilla. El resultado es más impactante que el tradicional retrato de aparato.

26 Toussaint, Manuel, op. cit., p. 168. Ver fig. 325. Se encuentra en la Pinacoteca Virreinal.

27 Cortés Arrese, Miguel, "Memoria breve del reformador Lorenzana", en SÁnchez SÁnchez, Isidro (coord.), El Cardenal Lorenzana y la Universidad de Castilla-La Mancha, Universidad de Castilla-La Mancha, 1999, p. 38.

28 Toussaint, Manuel, op. cit., p. 174.

29 Rodríguez Moya, Inmaculada, op. cit., p. 73.

30 Sierra Nava-Lasa, Luis, Francisco Antonio de Lorenzana, en Aldea Vaquero, Quintín; Marin Martínez, Tomás y Vives Gatell, José (dirs.), op. cit., p. 1347.

31 Extracto compendioso de las actas del Concilio IV Provincial Mexicano hecho y apuntado diariamente por uno de los que asistieron a él, en Ibid., pp. 475-476.

32 ZAHINo PeÑafort, Luisa, op. cit., p. 488.

33 LYNCH, John, "El reformismo borbónico e Hispanoamérica", en GUIMERÁ, Ángel (coord.), op. cit., p. 37. 
El año de 1789 sería crucial para Lorenzana. El 30 de marzo fue nombrado cardenal por el Papa Pío VI a la edad de 69 años. Éste es el privilegio con el que habitualmente sería representado. En un grabado del italiano Carlo Antonini ${ }^{34}$ se conmemora su elección como cardenal en 1789 (fig. 8). En la leyenda "Franciscus Antonius de Lorenzana Legionensis/ Archiepiscopus Toletanus S.R.E. Presbyter Cardinalis crea/ tus á SS. D. N. PIO VI in Consistorio secreto Palatii Vati/ cani die Lunae 30. Martii. 1789". Aparece firmado dentro del recuadro de la cartela $C$. Antonini sculp. y por debajo de la misma la institución emisora de la Real Camera Apostolica: Roma ex Calcographia R. C. A. Por encima el escudo pontificio y a la derecha el escudo de la familia Lorenzana.

El nuevo cardenal debía recoger su capelo y birrete directamente en Roma. Sin embargo, Lorenzana no pudo recoger el suyo hasta 1797 , momento en que fue enviado a Italia con la misión de consolar al Papa Pío VI ${ }^{35}$. En la correspondencia entre el embajador romano José Nicolás de Azara y Francisco Antonio de Lorenzana se deduce que la birreta la llevaría a España en 1789 el Príncipe de Santa Cruz, grande de España y amigo del diplomático y de Floridablanca ${ }^{36}$. El título que se le había concedido en 1789 era el de los SS. XII Apóstoles por lo que Lorenzana residiría en el Quirinal ${ }^{37}$. Este nombramiento tiene un carácter especial. Primeramente se realizó en consistorio privado destinado exclusivamente a este fin cuando lo usual era la elección en una promoción general. En segundo lugar, el rango de los cardenales presbíteros se reservaba a los cardenales que residían en Roma. La jerarquía cardenalicia estaba compuesta por el orden de los obispos, presbíteros y diáconos. Esta preeminencia en la persona de Lorenzana sólo puede entenderse a través de la mediación de Carlos III. Si bien, los cardenales sólo podían ser elegidos por el Pontífice, éste escuchaba las candidaturas que los monarcas católicos le presentaban ${ }^{38}$.

Una copia del grabado de Carlo Antonini lo efectúa Casiano López Durango en 1791 (fig. 9) tal y como se lee en la base: Casiano Lopez Durango Le grabó en Madrid año de 1791. En la leyenda "EL EMmo. Y EXmo. Sor. Dn. FRANCISCO ANTONIO/ Lorenzana, Presbítero Cardenal de la Santa Iglesia Romana, Arzobispo de Toledo \&a.". No existe ningún dato documental sobre este grabador cuyo apellido podría relacionarse con la familia del artista toledano Eugenio López Durango, aunque en la biografía de este último no aparece ningún familiar con el nombre de Casiano ${ }^{39}$.

Otro signo de la posición de Lorenzana dentro de las clases nobiliarias españolas era la Orden de Carlos III con la que había sido condecorado en $1772^{40}$. La plasmación física de esta Orden estaba formada por una cruz de oro de ocho puntas y en la orla central la imagen de la Inmaculada Concepción sostenida por una banda de seda ancha de color azul celeste con bordes blancos ${ }^{41}$.

${ }^{34}$ Carlo Antonini trabajó en Roma y Módena. Realizó grabados sobre 85 diseños de Salvatore Rosa, los retratos de Pío VI y varios cardenales como Tiraboschi y el propio Lorenzana. BenEzit, Emmanuel, Dictionnaire des peinares, sculpteurs, dessinateurs et graveurs, vol. I, Grünch, París, 1999, p. 370.

35 Rodríguez López-BreA, Carlos, Don Luis de Borbón. El cardenal de los liberales (1777-1823), J.C.C.M., Toledo, 2002, p. 64.

${ }^{36}$ LóPez De Toro, José, “Cartas de J.N. de Azara al Cardenal Lorenzana”, en Boletín de la Real Academia de la Historia, n. ${ }^{\circ} 161,1967$, p. 13

37 Fernández Collado, Ángel, "Semblanza de un singular arzobispo de Toledo", en Fernández Collado, Ángel (coord.), El cardenal Lorenzana, arzobispo de Toledo, I.T.S.I., Toledo, 2004, p. 25.

38 Rodríguez López-BreA, Carlos, op. cit., pp. 63-64.

39 Nicolau CAStro, Juan, Escultura toledana del siglo XVIII, I.P.I.E.T., Toledo, 1991, pp. 87-92.

40 Sierra Nava-Lasa, Luis, Francisco Antonio de Lorenzana, en Aldea Vaquero, Quintín, Marin Martínez, Tomás y Vives Gatell, José (dirs.), Diccionario de Historia Eclesiástica de España, CSIC, 5 vols., Madrid, 1972-1987, p. 1347.

${ }^{41}$ Rincón García, Wifredo, "Iconografía de la Real y Distinguida Orden de Carlos III", en Fragmentos, 12-13-14, 1988 , p. 149. 


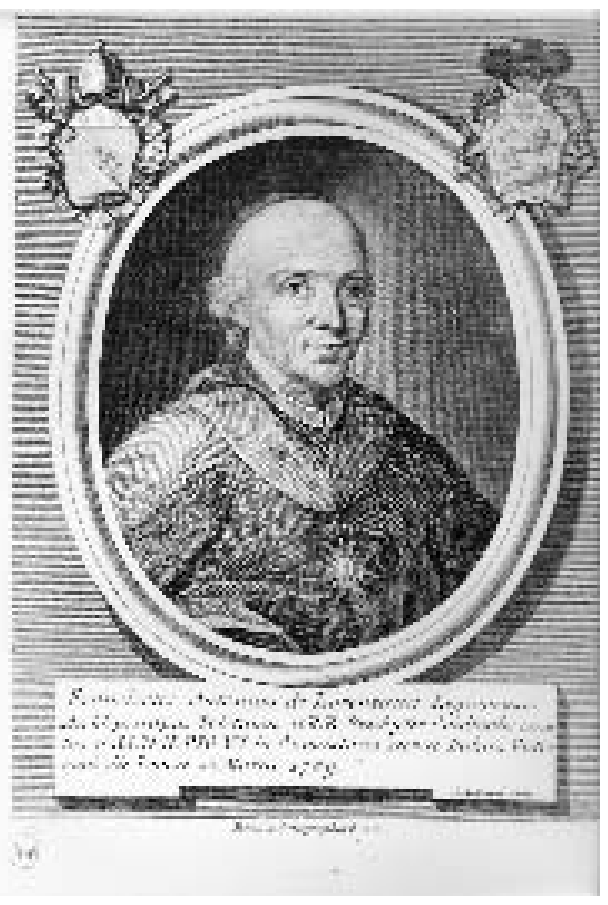

Fig. 8. Carlo Antonini, retrato de Francisco Antonio de Lorenzana en su elección cardenalicia, Madrid, Biblioteca Nacional.

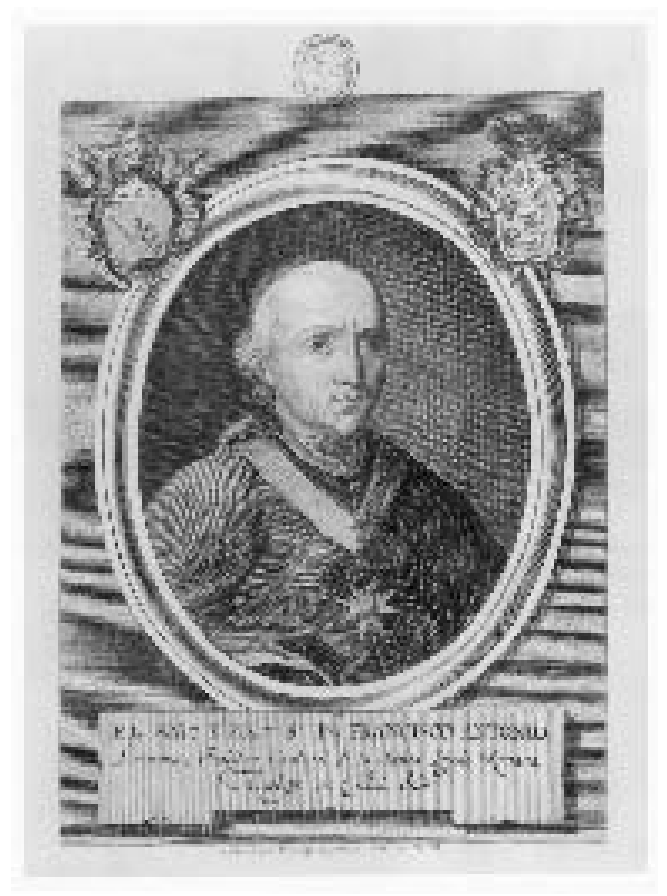

Fig. 9. Casiano López Durango, Francisco Antonio de Lorenzana, Madrid, Biblioteca Nacional.

El fuerte regalismo de Lorenzana expuesto durante su arzobispado mexicano le impulsaría a la mitra toledana y la concesión de la Orden de Carlos III con la que el monarca condecoraba a las personas que hubieran demostrado una vinculación especial con los intereses de la Corona. Este símbolo, junto con el birrete cardenalicio, forma la imagen proyectada y tipificada del prelado.

Otro de los grabados que resalta la faceta purpúrea del prelado leonés es el realizado por Buenaventura Salesa y Pietro Fontana en Roma ${ }^{42}$ (fig. 10). La producción conocida de Buenaventura Salesa (1756-1819) toma fuerza en la delineación del grabado, así conocemos su retrato de Aristóteles en El arte de poética de Aristóteles en castellano ${ }^{43}$ y las numerosas incisiones que aparecen en la Historia de la vida de Marco Tulio Cicerón ${ }^{44}$. Esta última obra fue escrita en inglés por Conyers Middleton y traducida al castellano por José Nicolás de Azara, embajador español ante la Santa Sede y a partir de 1799, embajador ante la República francesa. Salesa fue uno de los cinco pensionados que acompañó a Mengs en su vuelta a Italia en 1777. Cuando Mengs falleció, los pensionados quedaron bajo la protección de Azara siendo reconocido Salesa por su faceta como dibujante. En 1789 tras la muerte de Francisco Preciado de la Vega, director de los

42 Pietro Fontana nació en 1762 en Basano. Comienza su formación con el pintor Mengardi en Venecia, pero será en 1785 en Roma cuando se dedique definitivamente al grabado bajo las enseñanzas de Volpato y Morghen. Fue miembro de la Academia de San Lucas de Roma llegando a ejecutar un gran número de estampas. Murió en Roma en 1837. BENEZIT, Emmanuel, op. cit., vol. V, p. 557.

${ }_{43}$ Escrita por Joseph de Goya y Muniain e impresa por Benito Cano en 1798.

44 Impreso en cuatro tomos en la Imprenta Real por Lazaro Gayguer entre 1790 y 1804. 


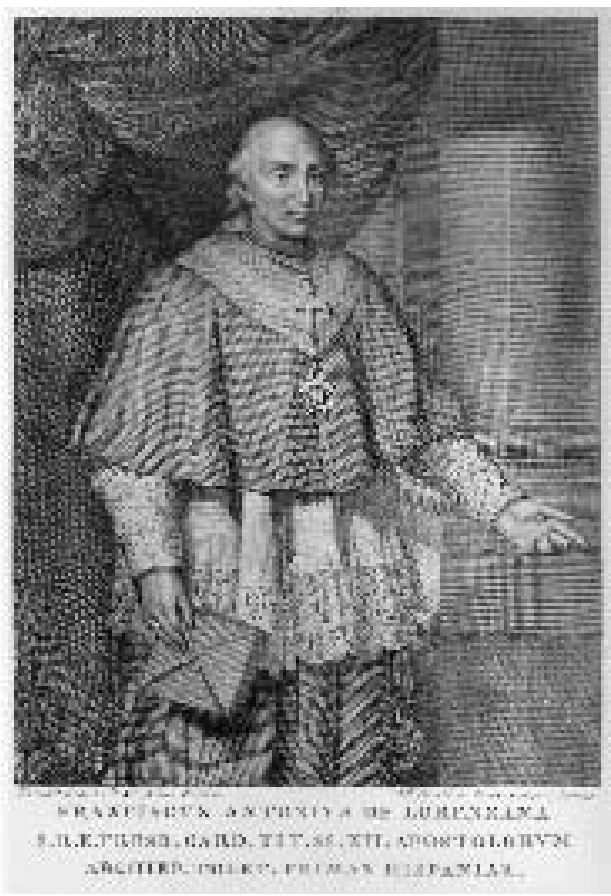

Fig. 10. Buenaventura Salesa y Petrus Fontana, Francisco Antonio de Lorenzana, Madrid, Biblioteca Nacional.

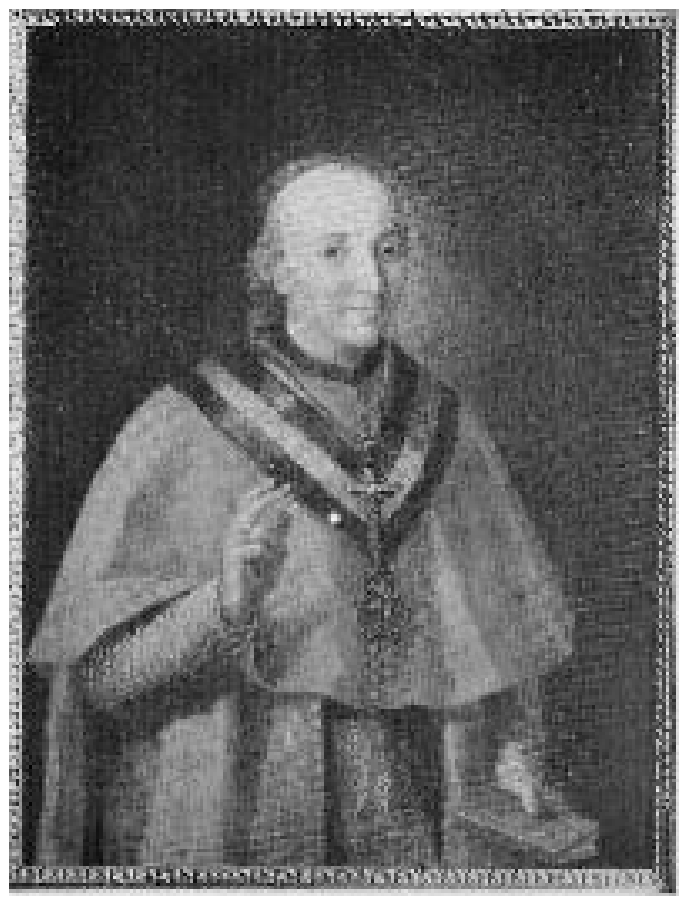

Fig. 11. Agustín Esteve, Francisco Antonio de Lorenzana, Madrid, Colección Conde de Finat.

pensionados españoles en Roma, Azara decidió establecer una escuela de dibujo en el Palacio de España dirigida por Salesa hasta su clausura en $1798^{45}$. La relación de José Nicolás de Azara con el cardenal Lorenzana permite lanzar la hipótesis de un encargo con los grabadores que tenía en su nómina. De hecho es el único grabado en donde aparece la leyenda del título cardenalicio de Lorenzana (SS. XII Apóstoles) pudiendo tratarse de una conmemoración del prelado iniciada por el diplomático español. La amistad entre ambos surge en 1748 cuando coincidieron en el Colegio de San Salvador en Salamanca donde Lorenzana llegaría a ser rector del mismo ${ }^{46}$.

La colaboración entre Buenaventura Salesa y Pietro Fontana se había dado en la Descrizione dell'aparato funebre per le esequie celebrat dalla Nazione Spagnuola nella sua Chiesa di S. Giacomo in Roma, alla Memoria di Carlo III... ${ }^{47}$ y en el retrato de Caeneades que aparece en la M. Tulii Ciceronis Opera Tomus decimus, impresión dirigida por P.I. Pereyra y publicada por la Tipografía Real en 1797. La leyenda del grabado hace referencia al título que ostentaba como cardenal y arzobispo de Toledo: "FRANCISCUS ANTONIUS DE LORENZANA/ S.R.E. PRESB. CARD. TIT. SS. XII. APOSTOLORUM/ ARCHIEP. TOLET. PRIMAS HISPANIAE".

45 JordÁn de UrRíes y de la Colina, Javier, "Los últimos discípulos españoles de Mengs (Ramos, Agustín, Salesa, Napoli y Espinosa)", en AA.VV., I Congreso internacional "Pintura española del siglo XVIII". Homenaje al Ilmo. Sr. Don José Luis Morales y Marín, Museo del Grabado español contemporáneo, Marbella, 1998, pp. 437-439, 442 y 447.

46 Sierra Nava-Lasa, Luis, op. cit., p. 63.

47 Impreso en Roma en 1789 en la imprenta de Marco Pagliarini. 
Supone una variante dentro de la usual caracterización de Lorenzana desconociendo la fuente que utilizó Salesa. Dispuesto como un retrato de aparato, la calidad del grabador viene avalada por la minuciosidad de los detalles. Las rocallas del vestido interior, el cabello y los reflejos de la banda de la Orden de Carlos III demuestran el alto nivel alcanzado.

En 1791, Luis Paret y Alcázar representó la ceremonia del juramento del heredero al trono, el futuro Fernando VII, celebrada el 23 de septiembre de 1789 en San Jerónimo el Real. En enero de 1790, el pintor presentó un dibujo preparativo al monarca (conservado en el Museo del Louvre) finalizándose el presente lienzo en $1791^{48}$. En la escena central se desarrollan los acontecimientos: a la izquierda el cardenal Primado de las Indias por delante del Consejo de Castilla; a la derecha los Reyes de España, Carlos IV y María Luisa, y el pequeño Don Fernando -con cinco años de edad- acompañado por su tío el Infante Don Antonio Pascual; y en el centro de la escena Francisco Antonio de Lorenzana recibiendo el besamanos de uno de los representantes en Cortes ${ }^{49}$. En $\mathrm{La}$ Gaceta de Madrid se encuentra una relación de los acontecimientos: "Estaba la Iglesia del Real Monasterio de S. Gerónimo vestida en todo su buque de varias sedas, con ricas guarniciones de oro, que señalaban las diferentes partes de su arquitectura. Se habia levantado un tablado al piso de la grada del altar mayor, y en toda la extensión del crucero. Al lado de la Epístola cerca del altar estaba revestido de pontifical el Emmo Sr Cardenal Arzobispo de Toledo, asistido de varios Capellanes de honor que servian los diaconales, el báculo, mitra, libro y palmatoria, y detras en un banco los demas Capellanes de honor que cupiéron" ${ }^{50}$. El siguiente párrafo muestra el proceso justamente anterior al inicio del juramento, en donde los asistentes debían jurar delante del Misal, el Crucifijo y de la mayor autoridad eclesiástica en España, Francisco Antonio de Lorenzana: "Luego que S. S. M. M. hiciéron oracion se empezó la Misa de pontifical que dixo el Emmo Sr.Cardenal Arzobispo de Toledo...Concluido se sentó el Arzobispo en una silla, que se le puso de espaldas al altar inmediata á la tarima, y el Sr. Patriarca colocó en una mesa delante del Sr. Arzobispo un Misal abierto, y un Crucifixo encima..." ${ }^{\prime 5}$. El acto final del acontecimiento es la propia jura de Lorenzana, quien lo hizo ante el cardenal patriarca de las Indias: "Llamó el Rey de Armas al Cardenal Arzobispo, y nombró al Cardenal Patriarca para recibirle el juramento, el que hecho prestó el pleyto homenage en manos del Marqués de Sta. Cruz. Besó su Eminencia las manos del Rey y Reyna, y Príncipe, y ocupó la silla que habia ocupado el Patriarca durante la funcion, habiendo mudado tambien de vestiduras como depuestos ámbos Eminencias, segun lo pedia el caso"52.

La pintura constituye un testimonio de importante interés documental clarificando las ceremonias y preeminencias celebrativas, en donde el arzobispo de Toledo ocupaba un lugar significativamente importante dentro de su condición eclesiástica en la sociedad ilustrada española.

Otra representación es la efectuada por Agustín Esteve y Marqués (fig. 11). Nació el 12 de mayo de 1753 en Valencia cursando sus estudios artísticos en la Academia de Bellas Artes de San Carlos. En 1772 pasa a la madrileña Real Academia de Bellas Artes de San Fernando ganando el primer premio de la tercera clase. Mientras continuaba su ascenso se convertiría en el pintor de la familia de los Osuna ganando de este modo una posición sólida en los círculos ar-

48 Vizuete Mendoza, Juan Carlos, Llamazares, Fernando y Martín Sánchez, Julio (coords.), op. cit., fig. 25, pp. 144-145.

49 Idem.

${ }^{50}$ Gaceta de Madrid, N. ${ }^{\circ}$ extraordinario de los días 21, 22 y 23 de septiembre de 1789, en SÁnchez Martín, Carlos, "El 'favor de la Memoria': La presencia del arzobispo de Toledo en el Madrid celebrativo", en PANIAGUA, Jesús (coord.), España y América entre el Barroco y la Ilustración (1722-1804). II Centenario de la muerte del Cardenal Lorenzana, Universidad de León, 2005, p. 499.

${ }^{51}$ Gaceta de Madrid, N. ${ }^{\circ}$ extraordinario de los días 21, 22 y 23 de septiembre de 1789, en SÁnChEZ Martín, Carlos, op. cit., p. 499.

${ }^{52}$ Gaceta de Madrid, N. ${ }^{\circ}$ extraordinario de los días 21, 22 y 23 de septiembre de 1789, en Idem. 


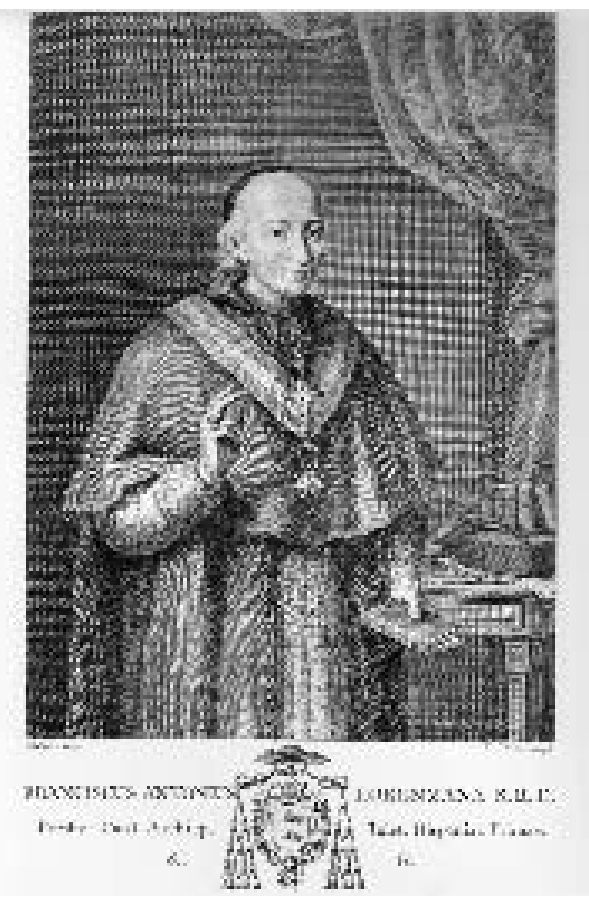

Fig. 12. Agustín Esteve y Manuel Salvador Carmona, Francisco Antonio de Lorenzana, Madrid, Biblioteca Nacional.

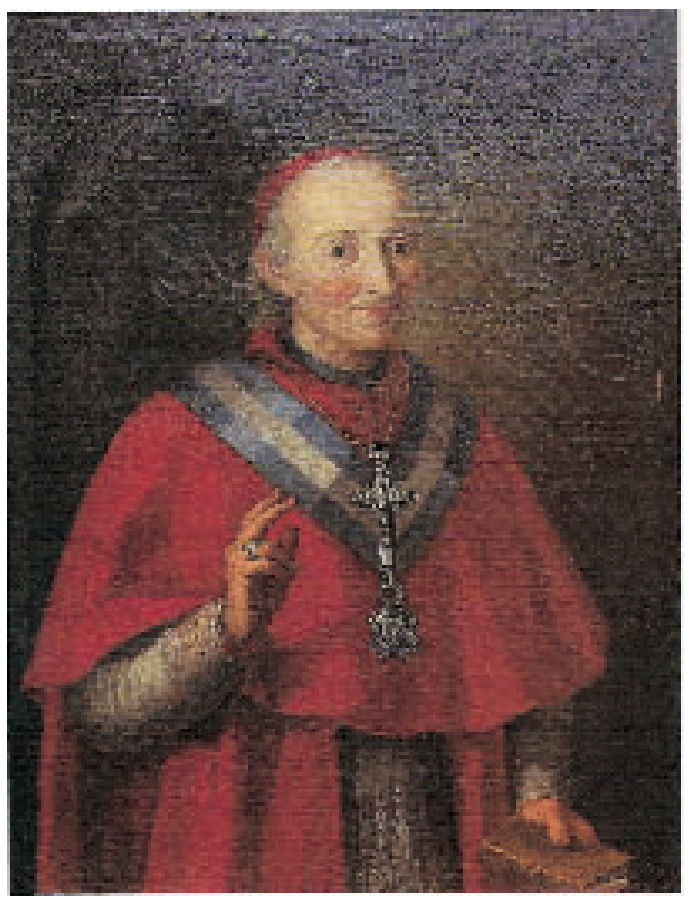

Fig. 13. Dionisio Palomares, Francisco Antonio Lorenzana, Toledo, Biblioteca Pública.

tísticos del momento. En 1780 sería ayudante de Goya realizando copias de los retratos efectuados por éste. Su fama como retratista fue tal que llegaría a convertirse en el pintor favorito de la reina María Luisa de Parma. Esta posición le llevaría a retratar a las más altas dignidades como al virrey de México, a los duques de Alba, Aliaga, Infantado, Medina de las Torres, Medinaceli... Retrataría a Fernando VII y a su hermano el Infante Don Carlos tras el paso del gobierno francés. Sin conocerse la fecha exacta de su muerte, es probable señalar el año de 1820 como final de su prolongada carrera ${ }^{53}$. En su retrato de Lorenzana ${ }^{54}$ los ojos llaman poderosamente la atención. Es una de las facetas más sobresalientes del pintor valenciano, ya que caracteriza habitualmente los ojos por su profundidad, oscuridad, penetración y gran tamaño transmitiendo la esencia del retratado. La importancia dada al rostro se completa con la sonrisa. Hemos comentado cómo Esteve cultivó mayoritariamente el género del retrato pudiendo observar las mismas constantes en lienzos como la Duquesa de Osuna ${ }^{55}$ o la Condesa de Miranda del Castañar ${ }^{56}$. El gusto por el detalle se advierte en la cruz pectoral, en la Orden de Carlos III y en las cenefas de la sobrepelliz del cardenal. Las telas gozan de amplitud de gamas, reflejos y sombras. El retratado lleva en su mano izquierda un libro entreabierto y la derecha se encuentra en actitud de bendecir. La personalidad del prelado es transmitida con la posición de sus manos y el rostro, hablando del carácter misericorde, afable y caritativo de Lorenzana. Para acentuar estas facetas el retratado se dispone

\footnotetext{
53 Soria, Martín, Esteve y Goya, Institución Alfonso el Magnánimo, Valencia, 1957, pp. 33-42.

54 Ibid., fig. 31.

55 SORIA, Martín, op. cit., fig. 1.

56 Ibid., fig. 3.
} 
sobre un fondo neutro perfilándose perfectamente la figura en un minucioso dibujo en donde la cabeza está llena de luz. El retrato de Esteve concuerda con la imagen historiográfica de Lorenzana, que radica en su atención moral y física hacia los pobres. Promulgaría varios memoriales relativos a este tema y de igual manera levantaría la Casa de la Caridad en Toledo y en Ciudad Rea ${ }^{57}$. La remodelación del Alcázar toledano como Casa de la Caridad supuso uno de los hitos sociales dentro de la España ilustrada y de este modo lo puso de manifiesto Ponz en su Viage de España.

El lienzo se encuentra fechado entre 1792 y 1798, momento en el que Esteve conseguiría su mejor producción a través de los brillos que provocaban un efecto de extrema sensibilidad y refinamiento ${ }^{58}$. La representación del prelado se enmarca dentro de la teoría psicológica del gesto, en donde el artista no debe imitar sin más la realidad sino indagar en el ser del representado. Este psicologismo tendrá su recepción en el mundo académico ${ }^{59}$. El sensualismo es una de las derivaciones de la emoción estética del neoclasicismo en la que la observación de la obra de arte produce placer.

Este cuadro sirvió como base al grabado que realizara Manuel Salvador Carmona (fig. 12) para el frontispicio de la edición romana del Misale Góthicum en $1804^{60}$. Manuel Salvador Carmona, nacido en 1734 en Navas del Rey (Valladolid) ${ }^{61}$, sería uno de los cuatro pensionados de la Academia madrileña para el arte del grabado en París en 1752, encontrándose tutelado por el grabador francés Nicolás Dupuis. Determinante sería su formación en la Academia parisina conocida por su excepcionalidad en el grabado. En 1759 sería nombrado "Agregado a la academia" y dos años más tarde consigue el título de académico gracias a los grabados de Boucher y Collin de Vermont ${ }^{62}$. Una vez en España irá acumulando numerosos títulos como académico de mérito en 1764, artista honorario de la Academia real de Toulouse en 1768, socio profesor de la Sociedad Bascongada de Amigos del País en 1775 y director del grabado en dulce de la Academia de San Fernando en 1777 y finalmente en 1783 Grabador de Cámara de S.M. ${ }^{63}$. También sería reconocido por las Academias de Zaragoza, Valencia y San Lucas de Roma ${ }^{64}$ convirtiéndose en uno de los artistas más laureados y conocidos de su tiempo. Mantendría relaciones con la mayoría de artistas de su tiempo, destacando a Francisco Javier Ramos, Joaquín Inza o José del Castillo y tuvo a José Nicolás de Azara como su protector en Madrid $^{65}$. En 1775 había grabado el dibujo de Maella de San Isidoro para la anteportada del Breviario mozárabe que publicase el mismo Lorenzana ${ }^{66}$. El

57 Cruz AlcañIz, Cándido de la, "Ciudad Real entre el Barroco y la Ilustración”, en PAniagua Pérez, Jesús (coord.), op. cit., pp. 469-487.

58 Ibid., fig. 54.

59 En 1772, Don Pedro de Silva declaraba: "Por más que con repetidos estudios haya llegado un Pintor á adquirir un gusto particular en representar la figura con naturalidad, no podrá sin embargo mover los afectos, si no los conoce como filósofo. El semblante, la postura, y aun el color de las carnes ha de dar á conocer el afecto de que está poseído el personage que se representa (...)". También Vicente Pignatelli: "La edad, la patria, el temperamento, el sexo y la profesión, que diferencian los síntomas de una pasión, podrá muy bien representarlas el Pintor con la variedad de vestido, tez de rostro, barba, cabellos, habitud de cuerpo, trage de la Nación, figura de cabeza, viveza, movimiento, ojos (...)", en Henares Cuéllar, Ignacio, La teoría de las artes plásticas en España en la segunda mitad del siglo XVIII, Universidad de Granada, 1977, pp. 62 y 67.

${ }^{60}$ SORIA, Martín, op. cit., 1957, p. 89.

${ }^{61}$ Carrete Parrondo, Juan, El grabado calcográfico en la España ilustrada, Club Urbis, Madrid, 1978, p. 39.

62 Carrete Parrondo, Juan, El grabado a buril en la España ilustrada: Manuel Salvador Carmona, Fábrica Nacional de Moneda y Timbre, Madrid, 1989, pp. 20-24.

${ }^{63}$ Ibid., pp. 26-29.

${ }^{64}$ Ibid., p. 30.

${ }^{65}$ Ibid., p. 31.

${ }^{66}$ Fernández Collado, Ángel y Vadillo Romero, Eduardo, "Los grabados del breviario mozárabe", en FernánDEZ Collado, Ángel (coord.), op. cit., pp. 247-251. 
grabado con la figura de Lorenzana aparece firmado en su ángulo inferior izquierdo A. Esteve pinx.t y en el derecho E. S. Carmona sculp.t. El lema aparece a ambos lados del escudo familiar con la peculiaridad de que a éste se sujeta la orden de Carlos III, uno de los símbolos que ayudaran a definir al cardenal. El texto es el siguiente: "FRANCISCUS ANTONIUS LORENZANA S.R.E. / Presbyt. Card. Archiep. Tolet. Hispaniar. Primas../ \&. \&.”. El grabado se comenzó en 1800 pagándose por él 6.000 reales y con el destino de formar el frontispicio de la edición romana de Antonio Fulgonio en $1804^{67}$. A partir del dibujo original de Esteve, Carmona introduce nuevos elementos como el cortinaje superior derecho, la mesa, papeles sueltos, libros y el birrete de cardenal. Si en el retrato de Esteve la figura se recortaba sobre un fondo neutro, Carmona introduce espacialidad a la representación a través de estos elementos que a la vez ayudan a definir al retratado. Respeta la esencia del lienzo original demostrando su facultad de precisión en los detalles como la cruz y la orden de Carlos III, las filigranas del vestido y el rostro. A pesar de la calidad del grabado, el artista no reproduce la sutileza del rostro del prelado tal y como vemos en el lienzo original, pero matizando que en este terreno Esteve era un especialista.

El retrato efectuado por Agustín Esteve se establecería como modelo al igual que ocurrió con el de Miguel Cabrera en México. En la Biblioteca Pública de Toledo nos encontramos con una copia del modelo de Esteve (fig. 13) que la crítica ha venido considerando del paleógrafo Francisco Javier de Santiago Palomares ${ }^{68}$. No se trata de él sino de su hijo. En un documento relativo al escritor hallado en el Archivo de la Real Academia de Bellas Artes de San Fernando encontramos el dato del oficio artístico de su hijo Dionisio: "Por que no se criasen mal quatro hijos, que tiene, los há criado el mismo dentro de su Casa, siendo él su Maestro, y sacandolos consigo al campo las fiestas, y feriados. Uno es el Xavier de qe se trata. Otro D. Antonio qe hoy sirve de Archivero al Ex. Sor. Mares. De Villafranca, mozo de extraordinaria habilidad para manejo de letras y papeles, aunque no sabe imitarlas. Otro D. Juan qe envio a Nueva España al abrigo de un Tio; y el quarto Dionisio, que tiene en casa, y se há aplicado á Pintor" 69 .

La única documentación que encontramos se refiere a su empleo en la ordenación de los libros y papeles que se encontraban en el Archivo de la Obra y Fábrica de la catedral en $1790^{70}$. Otra noticia conocida es su actividad como restaurador y la realización de treinta retratos entre arzobispos y personajes toledanos destinados principalmente a decorar las salas de la biblioteca arzobispal $^{71}$. Francisco Palomares pintaría un retrato del cardenal Gil de Albornoz para la galería de retratos de la biblioteca del cardenal Lorenzana ${ }^{72}$ pero antes de atribuirle certeramente su autoría hay que lanzar la hipótesis de la posible factura de su hermano Dionisio Palomares. De

${ }^{67}$ Archivo Histórico Nacional, Secc. Diversos, Bellas Artes, leg. 22, 327, en CARrete PARrondo, Juan, op. cit., 1989, p. 375 , cat. 375 .

${ }^{68}$ Llamazares Rodríguez, Fernando, "Imagen e imágenes de los arzobispos de Toledo", en Llamazares RodríGuez, Fernando y Vizuete Mendoza, Juan Carlos (coords.), op. cit., 2004, pp. 168; Vizuete Mendoza, Juan Carlos, "Retrato del Cardenal Lorenzana", en Vizuete Mendoza, Juan Carlos, Llamazares, Fernando y Martín SÁnchez, Julio (coords.), op. cit., pp. 282-283.

69 Archivo de la Real Academia de Bellas Artes de San Fernando (A.R.A.B.A.S.F.), Sign. 64-1/4.

70 Arellano García, Mario, "Nuevos datos para la historia de la capilla-parroquia de San Pedro, hoy capilla penitencial", en Toletum, n. ${ }^{\circ} 17,1985$, pp. 167-168.

71 Gutiérrez García-Brazales, Manuel, "Historia de los fondos antiguos", en Martínez Gill, Fernando (coord.), El Alcázar de Toledo: Palacio y Biblioteca, Junta de Comunidades de Castilla-La Mancha, Toledo, 1998, p. 91. La información viene recogida en los Libros de Mayordomía del palacio arzobispal de los años 1775-1801. También Archivo Diocesano de Toledo, SALA IV, libros 1908-1911, 1915-1917, 1919-1920, y SALA III, fondo cardenal Lorenzana, leg. 1.V.

72 Llamazares Rodríguez, Fernando, "Imagen e imágenes de los arzobispos de Toledo", en Llamazares RodríGuez, Fernando y Vizuete MendozA, Juan Carlos (coords.), op. cit., 2004, p. 160. 


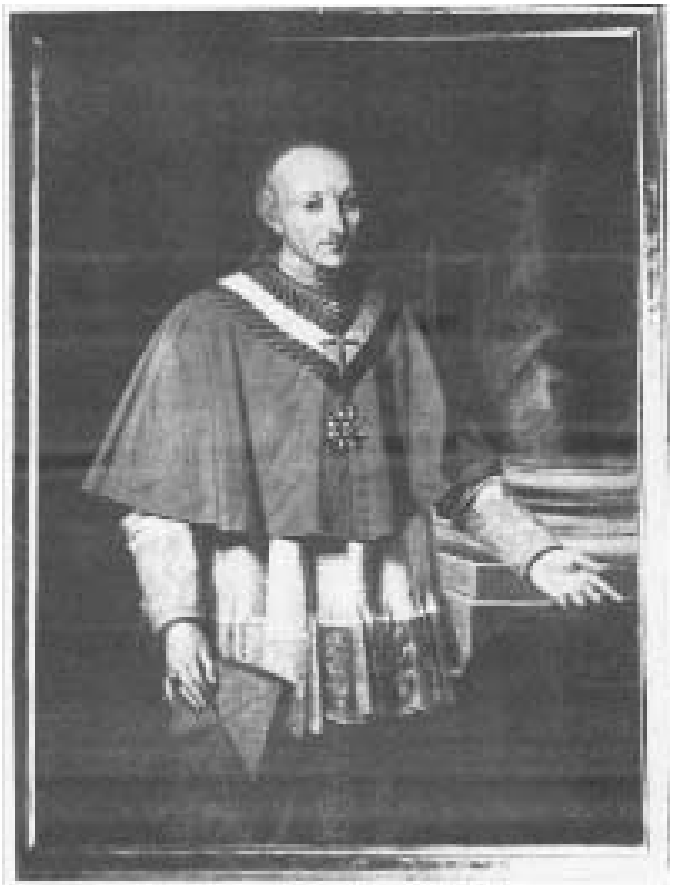

Fig. 14. Pedro Morales, Francisco Antonio de Lorenzana, Toledo, Casa de la Cultura.

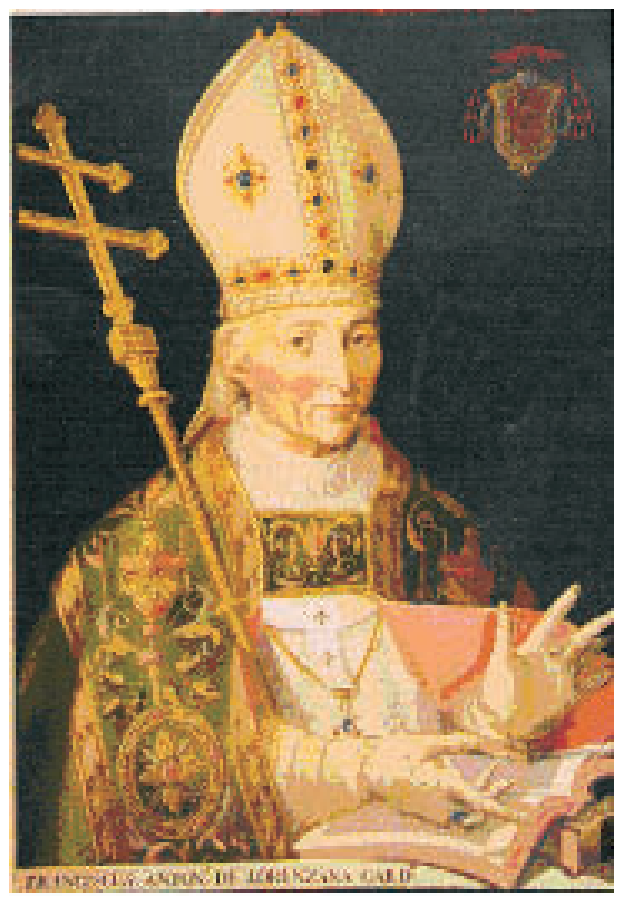

Fig. 15. Mariano Salvatierra, Toledo, Catedral.

hecho Dionisio es quien realiza la serie de personajes ilustres toledanos que se puede observar actualmente en la Biblioteca Pública de Toledo ${ }^{73}$.

Nada más conocemos sobre este pintor toledano. En similares circunstancias encontramos a Pedro Morales que efectúa el retrato de Lorenzana a partir del modelo del grabado de Salesa y Fontana. Aparece firmado Petrus Morales Toletanus pingebat. 1798 (fig. 14). La única noticia la obtenemos en 1805 cuando compone "un apostolado y Dolorosa original del Greco"74.

En 1801, cuando Lorenzana llevaba cuatro años en Italia, el Cabildo de la catedral de Toledo abona la cantidad de 3.000 reales a Mariano Salvatierra por la realización del retrato de Lorenzana (fig. 15) con destino a la Sala Capitular ${ }^{75}$. El retrato hace hincapié en su calidad de arzobispo -al que había renunciado en 1800- ya que el destino del mismo es la sala capitular donde se encuentran los retratos de todos los arzobispos que han ostentado la mitra toledana. Pontifical, mitra, palio y cruz arzobispal denotan su rango. En el escudo situado en la parte superior derecha cuelga la orden de Carlos III y cuatro borlas arzobispales faltando la quinta que era sinónimo del purpurado ${ }^{76}$.

73 Gutiérrez García-Brazales, Manuel, "Historia de los fondos antiguos”, en Martínez Gil, Fernando (coord.), op. cit., pp. 91 y 94.

74 Archivo de Obra y Fábrica de la Catedral de Toledo, Libro de 1805, fol. 148, en Nicolau Castro, Juan, op. cit., p. 133.

75 Nicolau Castro, Juan, "Un enigma resuelto. Los retratos del Cardenal Lorenzana para la Sala Capitular", en FERnÁNDEZ Collado, Ángel (coord.), op. cit., pp. 241-243.

${ }^{76}$ Llamazares lanza la hipótesis de haberse realizado antes de su cargo como cardenal y haberse añadido posteriormente el título. La autoría del retrato en 1801 supone el descuido del pintor al no incorporar la quinta banda de borlas. 


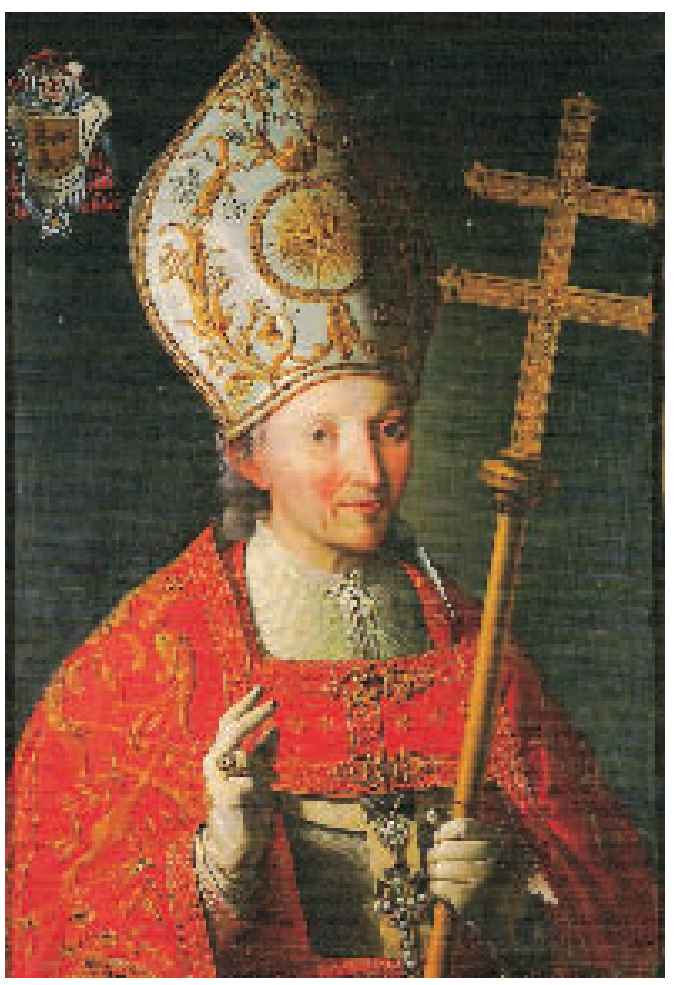

Fig. 16. Zacarías González, Toledo, Sala Capitular de la catedral.

Lorenzana, siendo aún arzobispo de Toledo, marcharía a Italia debido a las hostilidades con Godoy, permaneciendo en el extranjero hasta su fallecimiento. Participó en el cónclave de 1800 en el que el cardenal Chiaramonti sería erigido Papa con el nombre de Pío VII. Tras el mismo pasaría a Bolonia donde se hospedaría por algún tiempo en el Colegio Español de San Clemente. Allí le llegaría la noticia de que se deseaba su renuncia a la mitra toledana para concedérsela a Luis Antonio de Borbón y Vallabriga. Lorenzana acepta la decisión y pasa a Roma en septiembre de 1800. Allí continuaría hasta su muerte dando muestras de sencillez y pobreza, repartiendo limosnas e incluso ayudando a levantar una Academia en la Universidad de la Sapienza. Moriría el 17 de abril de 1804 siendo enterrado, por decisión suya, en la iglesia de la Santa Cruz de Jerusalén ${ }^{77}$. Una tela conservada en la romana iglesia de Monserrat es el único testigo visual de esta época italiana; realizada por Vincenzo Milione en 1802, tal y como aparece en el escrito que porta el cardenal que es figurado en su vejez ${ }^{78}$.

En 1807, tres años después de la muerte del arzobispo, Zacarías González Velázquez realizaría un nuevo retrato (fig. 16) basándose en el de Salvatierra. Con todos los atributos mencionados

En LlamaZares Rodríguez, Fernando, "Imagen e imágenes de los arzobispos de Toledo", en Llamazares RodríGueZ, Fernando y Vizuete MendozA, Juan Carlos (coords.), op. cit., p. 168.

77 Sobre la estancia italiana del cardenal, OlaEcheA, Rafael, "El cardenal Lorenzana en el Cónclave de Venecia", en Ridruejo, Pedro (coord.), op. cit., II vol. Del mismo autor El cardenal Lorenzana en Italia (1797-1804), CSIC, León, 1980.

78 Agradezco gentilmente a la restauradora Margarita Alonso el conocimiento de esta obra. En el papel que porta el prelado en la mano se puede leer "All Emo e Rvdo Sigr / Il Sigre Car de / Lorenzana / Per /Vincenzo Milione / al S. Sudario Pitto- / re". En el dorso se encuentra la fecha de realización. 
la calidad del lienzo supera al anterior. En el ángulo superior izquierda se encuentra el escudo con las cinco borlas cardenalicias. El cuadro está firmado "Zacharías Velásquez lo pintó en Madrid. Año 1807". En el anverso de la tela aparece en su borde inferior "FRANCs. CARDs. DE LORENZANA, RENUNC 22 DECEM 1800, OBIIT 17 APRILIS 1804"779. Bertha Núñez establece la posibilidad de que González Velázquez tuviera presente el modelo específico de Esteve como fuente principal, sin descontar el evidente paralelismo con el realizado por Mariano Salvatierra o el de Pedro Morales ${ }^{80}$. Otros lienzos que marcan su actividad en el arzobispado de Toledo son el San Ramón Nonato adorando al Santísimo Sacramento de la ermita del Santísimo Cristo de la Vera Cruz en Consuegra ${ }^{81}$, que sigue el modelo del San Pascual Bailón de Mengs, hoy en la Pinacoteca Albertina de Viena ${ }^{82}$. Respecto al cuadro de la iglesia de San Nicolás de Bari, solicita en octubre de 1806 el permiso real para llevar a cabo este lienzo, debido al atraso de pagos que tenía el artista y al descenso de los trabajos en los Reales Sitios ${ }^{83}$.

Las últimas representaciones conocidas son las que albergan el salón de actos del Palacio del cardenal Lorenzana en Toledo y la del rectorado de Castilla-La Mancha en Ciudad Real, ambas obras del siglo XX.

La orden de Carlos III y la faceta cardenalicia serán los símbolos de reconocimiento visual de Lorenzana en España, frente a su imagen arzobispal proyectada en México. El recorrido por el elevado número de representaciones del prelado leonés demuestra el enorme peso que tuvo en la Iglesia de su tiempo reafirmándose en su imagen como cardenal. El estudio de su persona nos desvela los mecanismos que permitieron el resurgimiento artístico de Toledo a finales del siglo XVIII. Pero no sólo a nivel artístico se muestra significativa su aportación, sino que como principal figura eclesiástica accedió, influyó y trató de reformar a todos los niveles sociales. En este sentido hay que señalar su elevada representación como exhibición de ser social, político y religioso. Una categoría lingüística socio-histórica aceptada a fines del siglo XVIII es el "favor de la memoria" 84 entendida como reconocimiento de la dignidad y prestigio del ser en su dimensión social. La actividad del prelado parte necesariamente de su intención por la valoración en su propio círculo social como figura de carácter ilustrado, humanitario y cultural. La apreciación de la imagen de Lorenzana en su época queda reflejada en su retrato.

Fecha de recepción: 15-XI-2006

Fecha de aceptación: 14-VI-2007

\footnotetext{
79 NúÑEz, Bertha, Zacarías González Velázquez (1763-1934), Fundación de Apoyo a la Historia del Arte Hispánico, Madrid, 2000, P-150, p. 214.

80 NúÑEZ, Bertha, op. cit., p. 214. También habría que mencionar el anónimo donde sostiene birrete negro en el Instituto Provincial de Toledo o el de Matías Moreno de la Real Academia de la Historia (Depósito Museo del Prado P-3423).

81 Ibid., P-104, p. 196.

82 Idem.

${ }^{83}$ NúÑEZ, Bertha, op. cit., doc. 75, pp. 41 y 372, P-98, p. 194.

${ }^{84}$ SÁnchez MARTín, Carlos, op. cit.
} 